\title{
Combatting Human African Trypanosomiasis in Uganda within a Decentralized Context
}

\author{
Sonia Menon \\ London School of Hygiene and Tropical Medicine
}

\section{A B STRACT}

While T.b rhodesiense continues to spread from its traditional focus in the South and East, cases of T.b gambiense continue to be recorded in north-western Uganda in the West Nile Region. Of particular worry is that these foci are currently separated by fewer than 150 kilometers, much of which is inhabited by tsetse flies. ${ }^{1}$ Starkly contrasting with previous ambitious unsuccessful top-down, continent-wide eradication campaigns, Human African Trypanosomiasis (HAT) control has now shifted from governmental to the individual level. In light of this imminent threat, the centre should remain sufficiently empowered to ensure provision of adequate technical expertise, as well as monitoring and evaluation. A literature review on HAT control activities in Uganda allowed for the identification of research gaps.

\section{INTRODUCTION}

Tsetse flies, and subsequently sleeping sickness, are usually found in remote sub-Saharan rural areas where health systems are weak or non-existent and usually has a low priority for public health authorities facing many competing challenges. In Uganda conflict is an important determinant of sleeping sickness and has contributed to disease resurgence as refugees and IDPs returning home after the conflict faced increase risk due to the vegetation and new tsetse habitat that had grown during their absence. ${ }^{2}$ Uganda is the only country to have endemic foci of both infectious agents of sleeping sickness, T.b Rhodesiense and T.b Gambiense which can be expected to merge in the absence of targeted intervention in central districts. ${ }^{3}$

T.b gambiense outbreaks, which are mostly confined to a human-fly human cycle with no animal reservoir are characterised by a long asymptomatic phase, high risk of treatment failure in late stage of disease. Early case treatment of human beings has been considered to be most effective against Gambian infections. In Uganda, the breakdown of the health care system following the conflict has hampered

Address for correspondence:

Sonia Menon,

16 Rue du Cambodge, Paris, France.

DOI: 10.5530/ijmedph.3.2011.12 surveillance and case treatment, leading to an increased duration of human infection.

T.b rhodesiense transmission to humans, on the other hand is influenced by the prevalence of the parasite in the animal reservoir. Studies have revealed how livestock has driven the epidemiology of trypanosomiasis, with a cow being five times more likely to infect a tsetse fly than a human. ${ }^{4}$ Rather than the migration of infected human beings, recent studies have shown how large-scale cattle restocking programmes, undertaken without any surveillance of trypanosome prevalence in the cattle moved in the restocking exercise may have compounded the spread of T.b rhodesiense in Uganda. ${ }^{5}$ Control of livestock infection and tsetse population, which had been compromised during the civil war, led to a resurgence of cases of T.b Rhodesiense in Soroti, Kaberamaido, Liran and Apac districts from 1999 to 2007. Sporadic epidemics have also been recorded in Hoima, Masindi and all islands of Lake Victoria. It is believed that it may have even gone further, perhaps to Gulu and Pader districts. $^{6}$

The aim of this review article is to explore the impact of public sector decentralization on the implementation, integration of approaches, livestock management, and tsetse control in Uganda. The objectives are threefold; firstly, explore how bottom-up T. rhodesiense control activities will require a sufficiently empowered centre to ensure effective local application of national policy. Secondly, argue that a 
sufficiently strong centre must be retained for adequately addressing the potential threat of the two strains merging. Lastly, key research areas will be identified.

\section{Public service decentralization}

Concurrently, the government of Uganda's vast reform of the public sector in the 1990s has been praised as "one of the most far-reaching local government reform programs in the developing world and one of the most radical devolution initiatives of any country at this time". ${ }^{7}$ The decentralization process transferred to all political and administrative authority from the central government to the local government authorities, including the power to approve district budgets. ${ }^{8}$ In the case of the Minister of Health, the shift of roles has been described as a change from a "Ministry of hospital services" to a "Ministry for health policy development."

In Uganda, public service decentralization has created a mismatch between health policy and health system, which in turn led to ineffective local application of national policy. ${ }^{10}$ The policy that Veterinary authorities in the Tororo District enacted to ensure that cattle traded is given a single dose of trypanocide before issuing movement permits to cattle traders is indicative of how control of trypanocides at local veterinary authorities may undermine national level recommendations. These national level recommendations advocate that chemoprophylaxis be continued on a regular basis to avoid the development of drug resistance, which might occur in breakthrough trypanosome populations that are exposed to waning, sub-trypanocides circulating drug concentrations. ${ }^{11}$

Also contributing to irregular use of prophylactic trypanocidal drugs, rather on an ad hoc basis whenever funds permit in villages in which cases occur ${ }^{12}$ may be the central government's inability to determine the total health care budget on population characteristics and health priorities. This in turn may further reduce its capacity to redress past inequities by allowing isolated rural areas to rely more heavily on central transfers.

In newly privatized systems, the responsibility for controlling endemic diseases of livestock, including trypanosomiasis has fallen upon the individual farmers supported by health assistants, extension workers and other local organisations, which are often ill-equipped for the tasks of control, diagnosis, and treatment ${ }^{13}$ and who might struggle to distinguish among common endemic diseases. ${ }^{14}$

\section{Restriction Application Method}

Lack of access to healthcare and diagnostic facilities, particularly in regions near the Sudanese border where there is civil unrest, resulted in the development of other strategies on how to manage the spread of the T.b rhodesiense strain being developed. Driven by the economic benefit in terms of animal production, as well as knowledge of the local epidemiological situation, integrating community involvement in tsetse control activities was considered as a key element in contributing to building sustainability. In 2007, the Stamping out Sleeping Sickness campaign, a public-private partnership was the first major project looking to control the disease through removing and preventing re-infection in the principal animal reservoir in Uganda. ${ }^{15}$ DIFD funded tsetse and trypanosomiasis research revealed that treatment targeting only larger-sized adult cattle may constitute a cost effective control measure. This bottom-up approach, which only requires a minimum of training, is designed to break the tsetse fly transmission cycle and an initial small incidence of disease must be accepted before control will be achieved. The "restricted application method", which consists of only needing to treat about a quarter of the cattle, is now being used to treat approximately 200,000 cattle in Uganda. ${ }^{16}$

However, without regularly held focus groups as a research technique by specialised HAT national staff to assess livestock holders' epidemiological knowledge of sleeping sickness, acceptance and knowledge of the pour-on technology in terms of its need for reapplication, the "restricted application method" may not prove to be sustainable.

In light of a possible overlap of the two disease foci leading to changed genetic material, ongoing entomological and veterinary monitoring will also be crucial. This will provide a better understanding of the dynamics of an optimal insecticide treatment regime, including the frequency of reapplication, as well as resistance monitoring insecticidetreated cattle.

To this end, ensuring quality and effectiveness of surveillance and public health response of the pour-on technology in an environment of decentralization will also need to be closely examined. Given the many uncertainties, employing local rural deployment capacity and infrastructure to undertake active surveillance to supplement passive surveillance at national level may not be capable of absorbing the additional functions that implementing the pour on technology may entail.

\section{Integration of HAT control in the primary health care system}

Integration of HAT control in the primary health care system and community involvement in surveillance and control has also had a major impact on the organisation and implementation of sleeping sickness control. Between 1997 and 2006, the T.b gambiense formed 97\% of the total 
cases reported at continental level responded well to intensive control activities and the number of people under active surveillance increased, and the number of new cases decreased. ${ }^{17}$ Control programmes can now undergo the transition from a humanitarian crisis intervention programme to professional disease containment and surveillance where individual case management can again be given more consideration. ${ }^{18}$ This would include addressing the increasing drug resistance that the frequency and extent of the use of standard first line drug for early stage of T.b gambiense, pentamidine, and late stage Melarsoprol is causing. Latestage cases refractory to melarsoprol have been observed in up to $30 \%$ of patients in some foci in north-western Uganda. ${ }^{19}$

To sustain the recent epidemiological downward trend in the T.b gambiense, tackling drug resistance will require better diagnosis and staging. ${ }^{20}$ Even though serology has played a major part in active case identification, positive results from the Card agglutination Trypanosomiasis Tests (CAT'T) are not sufficiently sensitive and specific to establish a definitive diagnosis and require further parasitological tests. ${ }^{21}$ False-positive results can occur in patients with malaria and other parasitic diseases such as transient infection by nonhuman trypanosomes. ${ }^{22}$ Given the high toxicity of melarsoprol, the most widely used treatment for secondstage, it is imperative that both diagnosis and staging of the disease be highly accurate. As long as there is no safe and effective drug available to treat both stage of the disease, systemic stage determination will remain necessary, which will require well-trained staff capable of managing patients using any HAT stage drugs. ${ }^{23}$

Even though district level T.b gambiense control activities have been successful and cases have decreased steadily, overlap in the distribution of these parasites will undoubtedly complicate diagnosis and result in inappropriate treatment for critically ill patients. It will therefore also be necessary to develop a novel approach for surveillance and control adapted to the new requirements of monitoring drug resistance. The two foci converge may increase the number of treatment failures of late stage T.b gambiense and thereby further compromise treatment options for T. $b$ rhodesiense. ${ }^{24}$ This approach would require the active participation of a strengthened health system capable of implementing surveillance and control activities, buttressed by specialized HAT national staff, instead of devolving major responsibilities onto the existing health services of remote rural areas inappropriately trained. ${ }^{25}$

For the T.b rhodesiense, there is still no equivalent to the CATT widely available ${ }^{26}$ and its diagnosis relies on microscopy of blood, lymph or cerebrospinal fluid is inherently difficult to diagnose and health facilities in rural areas are usually scarce. In Uganda, an estimated 12 deaths caused by sleeping sickness go undetected for every one reported. ${ }^{27}$ A study in Eastern Uganda has shown that long delay in diagnosis and therefore in treatment can be attributed to health seeking patterns as well as to the service provider failing to diagnose sleeping sickness among symptomatic individuals. ${ }^{28}$ Even in stable situations long delays occur in diagnosis, during which patients will deteriorate, possibly irreversibly, while remaining a reservoir of infection. ${ }^{29}$

Whilst late stage cases of both diseases are treated with melarsoprol and eflornithine only in case of treatment failure for T.b gambiense, pentamidine, the first line drug for T.b gambiense is not effective against early stage $T b$ rbodesiense, ${ }^{30}$ which is treated with suramin. In light of the two strains merging, real time monitoring would be recommended at regional and national surveillance centres targeting livestock and human patients, using new molecular biology techniques, ${ }^{31}$ such as the SRA gene for genotype identification of the two strains to ensure that inappropriate treatments are not prescribed in early stage disease.

\section{CONCLUSION}

The continent-wide importance of these two parasite species overlapping is such that a properly equipped screening laboratory and staff training should be set up as a matter of urgency to tackle the likely increase of complexity and difficulty in subsequent control initiatives. ${ }^{32}$ This might take the form of an internationally funded and locally managed facility under the supervision of the relevant authorities in Uganda.

Whilst decentralized basic health services may have been appropriate hitherto in areas affected only by T.b gambiense, ${ }^{33}$ with the merger looming, an effective T.b rhodesiense control and T.b gambiense design needs specialized teams and health care systems working synergistically. Furthermore, T.b rhodesiense control must incorporate a multifaceted approach, requiring better coordination between medical, veterinary and entomological agencies. An ill-conceived decentralisation model that results in uncoordinated distribution of power between different levels of governments, inadequate planning, weak management may undermine the multifaceted approach required to use to combat T.b rhodesiense.

Although decentralization of veterinary and health care services may result in control of T.b rhodesiense being tailored to local settings, an important gap remains in conveying appropriate information to farmers about control strategies, as well as getting epidemiological information to experts and policy makers who need reliable facts for advising medical and veterinary personnel and extension workers. ${ }^{34}$ Research remains to be undertaken as to be capable of 
striking the right balance between the Government and community involvement. Community involvement must be fostered but not to the detriment of the centre, which needs to be sufficiently empowered to derive epidemiological knowledge from local communities and susbequently implement adequate preventive measures.

Moreover, in light of the highly regulatory role that will be required from the central government in controlling T.b rhodesiense, research should be conducted to assess whether the centre has been able to develop competencies to switch from health provision, policy-making to a more passive role of regulating within such as limited time frame and is empowered to enforce regulation effectively.

Advances in identification techniques, including the future use of SRA gene as a sensitive detection system to monitor the tripartite relationship between drug, host and parasite, and cross-resistance between veterinary trypanocides and HAT drugs will require the collaboration and expertise of local, national, and international clinicians, veterinarians, epidemiologists and laboratory scientists. This highlights the urgent need for capacity building for research and control of HAT in endemic countries through strengthening laboratories and research centres, training scientists, and encouraging networking. This can only be achieved with a sufficiently empowered centre, capable of maintaining a specialized central structure at national level to ensure the coordination and overall technical assistance.

As the experience of many other countries bears out, decentralization represents a threat to the viability of vertical control programmes. ${ }^{35}$ In Uganda, at district level, the implementation of malaria control activities has frequently been disappointing. ${ }^{36}$ In light of the imminent merging of a vector-borne disease with a zoonotic vector borne disease, along with a potential lethal cocktail of it being combined with HIV, more than ever the centre should be capable of ensuring adequate technical expertise at decentralized levels of services, sufficient budgets, capacity building, as well as adequate monitoring and evaluation.

\section{REFERENCES}

1. Lea Berrang Ford. Civil conflict and sleeping sickness in Africa in general and Uganda in particular; Conflict and Health 2007 http://www. conflictandhealth.com/content/1/1/6 accessed online on March $14^{\text {th }} 2008$.

2. Lea Berrang Ford. Civil conflict and sleeping sickness in Africa in general and Uganda in particular. Conflict and Health 2007. http://www. conflictandhealth.com/content/1/1/6 accessed online on March $14^{\text {th }} 2008$.

3. Kim Picozzi, Eric M Fèvre (2005) Sleeping sickness in Uganda: a thin line between two fatal diseases. British Medical Journal http://www.bmj.com/ cgi/content/full/331/7527/1238 accessed online on February $24^{\text {th }}, 2010$.

4. DFID Animal Health programme; Trypanosomiasis and improved diagnostics. Animal Health Programme http://www.dfid-ahp.org.uk/index. php?section=3\&subsection=24 March $20^{\text {th }}, 2010$.
5. O C Hutchinson, E M Fèvre, Lessons learned from the emergence of a new Trypanosoma brucei rhodesiense sleeping sickness focus in Uganda. The Lancet Infectious Diseases Vol 3, 2003 http://www.dfid-ahp.org.uk/ downloads/R7596-Hutchinsonetal.pdf accessed online on January $10^{\text {th }}$, 2010.

6. All Africa, Uganda: Sleeping disease reaching alarming levels. $2008 \mathrm{http}: / /$ allafrica.com/stories/200805120552.html accessed online February $28^{\text {th }}$, 2010.

7. Mitchinson, Robin. Devolution in Uganda: An experiment in local service delivery, in:Public Administration and Development, 2003:23(3), pp. 241-248.

8. Anders Jeppsson. Decentralization and National Health Policy Implementation in Uganda - a Problematic Process. Department of Community Medicine Malmö University Hospital, Lund University, Sweden. 2004 http://www.lub.lu.se/luft/diss/med_963/med_963_kappa.pdf accessed online February $12^{\text {th }}, 2010$.

9. Anders Jeppsson. Decentralization and National Health Policy Implementation in Uganda - a Problematic Process. Department of Community Medicine Malmö University Hospital, Lund University, Sweden-2004 http://www.lub.lu.se/luft/diss/med_963/med_963_kappa. pdf accessed online February $12^{\text {th }}, 2010$.

10. Leach, T.M. and Roberts, C.J. Present status of chemotherapy and chemoprophylaxis of animal trypanosomiasis in the eastern hemisphere. Pharmacol. Ther. 1981 13, 91-147.

11. Leach, T.M. and Roberts, C.J. Present status of chemotherapy and chemoprophylaxis of animal trypanosomiasis in the eastern hemisphere. Pharmacol. Ther. 1981 13, 91-147.

12. Susan C. Wellburn, Paul G. Coleman et al.Crisis, what crisis? Control of Rhodesian sleeping sickness. Trends in Parasitology. 2006 Vol 22. No.3.

13. Chilonda, P. and Van Huylenbroeck, G. Attitude towards and uptake of veterinary services by small-scale cattle farmers in Eastern province, Zambia. Outlook Agric. 2001 30, 213-218.

14. Susan C. Wellburn, Paul G. Coleman et al Crisis, what crisis? Control of Rhodesian sleeping sickness. Trends in Parasitology. Vol 22. No.3 March 2006.

15. Maina Warur. Livestock Trade is Culprit in Sleeping Sickness Spread. All Africa.com. $2010 \mathrm{http} / / /$ allafrica.com/stories/201001220854.html accessed online on February $28^{\text {th }}, 2009$.

16. Research for Development. Case Studies, Fighting Sleeping disease in Uganda. 2007 http://www.research4development.info/caseStudies. asp?ArticlelD=50095 Accessed online August 17 $7^{\text {th }}, 2009$.

17. Simarro PP, Jannin J, Cattand $P$ Eliminating Human African Trypanosomiasis: Where Do We Stand and What Comes Next? PLoS Med. 2008 5(2): e55. doi:10.1371/journal.pmed.0050055 accessed online February $26^{\text {th }}, 2010$.

18. Walter $O$ Inojosa, Inacio Augusto. Diagnosing human African trypanosomiasis in Angola using a card agglutination test: observational study of active and passive case finding strategies; British Medical Journal. 2006 http://www.ncbi.nlm.nih.gov/pmc/articles/PMC1482336/ accessed online on December 24 2009.

19. J. Pépin, B. Mpia. Randomized controlled trial of three regimens of melarsoprol in the treatment of Trypanosoma brucei gambiense trypanosomiasis Transactions of the Royal Society of Tropical Medicine and Hygiene, 2009 Volume 100, Issue 5, Pages 437-441.

20. Simarro PP, Jannin J, Cattand $P$ Eliminating Human African Trypanosomiasis: Where Do We Stand and What Comes Next? PLoS Med. 2008 5(2): e55. doi:10.1371/journal.pmed.0050055 accessed online February $26^{\text {th }}, 2010$.

21. Simarro PP, Jannin J, Cattand P. Eliminating Human African Trypanosomiasis: Where Do We Stand and What Comes Next? PLoS Med 2008 5(2): e55. doi:10.1371/journal.pmed.0050055 accessed online February $26^{\text {th }}, 2010$

22. Magnus, E., T. Vervoort, and N. Van Meirvenne. A card-agglutination test with stained trypanosomes (C.A.T.T.) for the serological diagnosis of T. b. gambiense trypanosomiasis. Ann. Soc. Belg. Med. Trop 1978. 58:169-176

23. Simarro PP, Jannin J, Cattand P. Eliminating Human African Trypanosomiasis: Where Do We Stand and What Comes Next? PLoS 
Med 2008 5(2): e55. doi:10.1371/journal.pmed.0050055 accessed online February $26^{\text {th }}, 2010$.

24. Simarro PP, Jannin J, Cattand P. Eliminating Human African Trypanosomiasis: Where Do We Stand and What Comes Next? PLoS Med. 2008 5(2): e55. doi:10.1371/journal.pmed.0050055 accessed online February $26^{\text {th }}, 2010$.

25. Simarro PP, Jannin J, Cattand P. Eliminating Human African Trypanosomiasis: Where Do We Stand and What Comes Next? PLoS Med . 2008 5(2): e55. doi:10.1371/journal.pmed.0050055 accessed online February $26^{\text {th }}, 2010$.

26. François Chappuis, Louis Loutan. Options for Field Diagnosis of Human African Trypanosomiasis Clinical Microbiology Reviews, 2005 p. 133-146, Vol. 18, No. 1.

27. Odiit, M. et al. Quantifying the level of under-detection of Trypanosoma brucei rhodesiense sleeping sickness cases. Trop. Med. Int. Health. 2005 10, 840-849.

28. Odiit M, Shaw A, et al; Assessing the patterns of health-seeking behaviour and awareness among sleeping-sickness patients in eastern Uganda. Ann Trop Med Parasitol Jun. 2004. 98(4):339-48. http://www. ncbi.nlm.nih.gov/pubmed/15228715 accessed online on February $24^{\text {th }}$, 2010.

29. Walter O Inojosa, Inacio Augusto et al. Diagnosing human African trypanosomiasis in Angola using a card agglutination test: observational study of active and passive case finding strategies BMJ. 2006 June 24;
332(7556): 1479. http://www.ncbi.nlm.nih.gov/pmc/articles/PMC1482336/ accessed online February $24^{\text {th }}, 2010$.

30. Kim Picozzi, Eric M Fèvre Sleeping sickness in Uganda: a thin line between two fatal diseases. British Medical Journal 2005 http://www.bmj. com/cgi/content/full/331/7527/1238 accessed online on February $24^{\text {th }}$, 2010.

31. Kim Picozzi, Eric M Fèvre Sleeping sickness in Uganda: a thin line between two fatal diseases. British Journal of Medicine. $2005 \mathrm{http}: / / \mathrm{www}$. bmj.com/cgi/content/full/331/7527/1238 accessed online on January $24^{\text {th }}$, 2010.

32. Simarro PP, Jannin J, Cattand $P$ Eliminating Human African Trypanosomiasis: Where Do We Stand and What Comes Next? PLoS Med 2008 5(2): e55. doi:10.1371/journal.pmed.0050055 accessed online February $26^{\text {th }}, 2010$.

33. Simarro PP, Jannin J, Cattand $P$ Eliminating Human African Trypanosomiasis: Where Do We Stand and What Comes Next? PLoS Med. 2008 5(2): e55. doi:10.1371/journal.pmed.0050055 accessed online February $26^{\text {th }}, 2010$.

34. Brightwell, B. et al. Reality vs rhetoric - a survey and evaluation of tsetse control in East Africa. Agric. Human Values 2001 18, 219-233.

35. Paul Hutchinson. Health Care in Uganda, Selected Issues, World Bank Discussion Paper. 1999 n.404.

36. Paul Hutchinson Health Care in Uganda, Selected Issues, World Bank Discussion Paper. 1999 n.404. 